Research Article

\section{Depression and anxiety in patients with suspected renal artery stenosis}

\section{Ludvig Hallberg $^{1 *}$, Anders Gottsater ${ }^{2}$, Anders Isaksson ${ }^{3}$ and Asa Westrin ${ }^{1}$}

${ }^{1}$ Department of Clinical Sciences, Division of Psychiatry, Lund University, Lund, Sweden

${ }^{2}$ Department of Vascular Diseases, Malmö University Hospital, Lund University, Malmö, Sweden

${ }^{3}$ Department of Laboratory Medicine, Division of Clinical Chemistry, Lund University, Lund, Sweden

\section{Abstract}

Objective: To investigate the occurrence of depressive and anxiety disorders in patients remitted for endovascular treatment of renal artery stenosis (RAS), and whether symptoms of depression and anxiety can be reduced after the treatment of RAS with percutaneous transluminal renal angioplasty (PTRA).

Methods Patients: Selected for renal angiography with pressure measurement in the renal arteries due to suspected RAS were invited to participate in the study. 37 patients agreed to answer a questionnaire. Eighteen patients also agreed to a clinical psychiatric examination including the International Neuropsychiatric Interview (M.I.N.I. 6.0) to be diagnosed according to the DSM-IV.

Results: Twenty-one of the 37 patients completing the questionnaire were found to have a pressure gradient of $\geq 10 \mathrm{mmHg}$ at angiography, indicating significant stenosis. Ten of the 18 examined patients met the criteria for current DSM-IV anxiety diagnosis and two patients had a current depression. Three of the 18 examined patients had previously made a suicide attempt.

Conclusion: The results of this study suggest that patients with suspected RAS have a high psychiatric comorbidity, as $56 \%$ of the patients undergoing psychiatric examination met the DSMIV criteria for a current anxiety disorder.

\section{More Information}

*Address for Correspondence: Ludvig Hallberg, Department of Clinical Sciences, Division of Psychiatry, Lund University, Lund, Sweden, Tel: +4646174801 Email: Ludvig.Hallberg@med.lu.se

Submitted: January 12, 2021

Approved: September 03, 2021

Published: September 06, 2021

How to cite this article: Hallberg L, Gottsater A, Isaksson A, Westrin A. Depression and anxiety in patients with suspected renal artery stenosis Insights Depress Anxiety. 2021; 5: 016-024.

DOI: 10.29328/journal.ida.1001026

Copyright: @ 2021 Hallberg L, et al. This is an open access article distributed under the Creative Commons Attribution License, which permits unrestricted use, distribution, and reproduction in any medium, provided the original work is properly cited.

Check for updates

OPEN ACCESS

\section{Introduction}

Depressive and anxiety disorders are among the most common public health problems in the world. The lifetime prevalence of major depressive disorders is about $16 \%$ [1] and the 12-month prevalence $6.6 \%$, while the lifetime prevalence of anxiety disorders is about $29 \%$ [2]. The Lundby study reported a lifetime prevalence of anxiety (up to 60 years of age) of $9.9 \%$ in men and $19.7 \%$ in women [3].

Among the well-known biological mechanisms behind affective disorders are disturbances in the serotonergic system [4], the hypothalamic-pituitary-adrenal (HPA) axis [5], and the immune system [6]. It has also been suggested that the renin-angiotensin-aldosterone system (RAAS) may be affected in some patients with depression [7], and in some with anxiety.
The RAAS prevents low blood pressure (BP) by means of a coordinated effect of the hormones angiotensin and renin. Angiotensin II stimulates the release of aldosterone from the adrenal gland. Aldosterone is a steroid that acts on mineralocorticoid receptors (MR). It reduces the loss of sodium ions and water from the kidneys, which leads to increased extracellular fluid, a greater blood volume and an increase in BP [8]. Constriction of the renal artery (renal artery stenosis, RAS) lowers the intrarenal pressure, thereby stimulating the RAAS, causing persistent hypertension $[9,10]$. RAS can remain an undetected cause of hypertension for several years, apart from causing deterioration of renal function [11]. RAS leading to severe hypertension or renal dysfunction can be treated with percutaneous transluminal renal angioplasty (PTRA) [12] with stenting. However, indications for treatment are the subject of debate, as the results of large randomized studies have not been convincing $[13,14]$. 
Interestingly, the RAAS also affects brain function [15], and there is growing evidence that the RAAS may have a psychopathological influence [7]. MR are found in several regions of the brain, including the hippocampus, the amygdala and the nucleus accumbens [16].

In recent years, several studies have shown that rats treated with aldosterone exhibit symptoms of depression and anxiety $[17,18]$. Moreover, MR seem to be involved in the response to antidepressant therapy in rats. Studies have shown both up- [19,20] and downregulation [21] of MR after antidepressant therapy.

The findings of some clinical studies support the role of the RAAS in depression. For example, increased levels of aldosterone have been found in patients suffering from depression [22]. Furthermore, in a study by Sonino, et al., six of ten patients with primary aldosteronism (PA) suffered from an anxiety disorder [23]. In a follow-up study, 23 healthy controls were compared to 23 patients with essential hypertension (EH) and 23 with PA [24]. Twelve of the 23 patients with PA suffered from an anxiety disorder, compared to four of the 23 with EH. Patients with PA also scored higher when rated for stress than the EH patients, indicating that not only hypertension, but also the overproduction of aldosterone, causes anxiety.

Little research has been conducted on the potential comorbidity between RAS and psychiatric illness. This study was therefore carried out to investigate the following two hypotheses: the occurrence of depressive and anxiety disorders is higher in patients remitted for endovascular treatment of RAS, and that symptoms of depression or anxiety can be reduced after the treatment of RAS with PTRA.

\section{Experimental procedures}

\section{Patients}

The study was approved by the Lund University Medical Ethics Committee (No. 2013/310). All the participants gave their written informed consent to participate.

The patients were recruited from the Vascular Centre, Skåne University Hospital, Malmö, southern Sweden, between August 2013 and June 2015. Patients selected for renal angiography with pressure measurement in the renal arteries due to suspected RAS were invited to participate in the study. All patients had treatment-resistant hypertension, signs of kidney dysfunction, or both, and pathological findings at magnetic resonance angiography of the renal arteries, suggesting RAS. The patients included in the study were asked to fill in a questionnaire and self-rating scales. They were also offered a clinical psychiatric examination. They were also informed that their decision to participate, or not, in the study would not affect their medical or interventional treatment.

During the study period, 71 patients met the inclusion criteria, 12 of which were excluded from the study: ten were unreachable by phone or did not speak Swedish, and two were hospitalized due to severe concomitant somatic disease. The remaining 59 were identified as potential participants in the study (Figure 1). Of these 59 patients, 37 agreed to answer the questionnaire part, including an agreement for the principal investigator to screen the medical records. The selfrating scales Montgomery-Asberg Depression Rating Scale (MADRS-S) [25] and Hospital Anxiety and Depression scale (HAD) [26] were added to the questionnaire part after 12 patients had been included (twelve patients with completed questionnaires and seven patients with completed clinical examinations). Eighteen patients also consented to the psychiatric clinical examination, which also included the HAD for the first seven patients. A total of 25 MADRS-S scores and 29 HAD scores were collected at baseline. Data on the somatic morbidity of the 18 patients who underwent the psychiatric examination are given in Table 1.

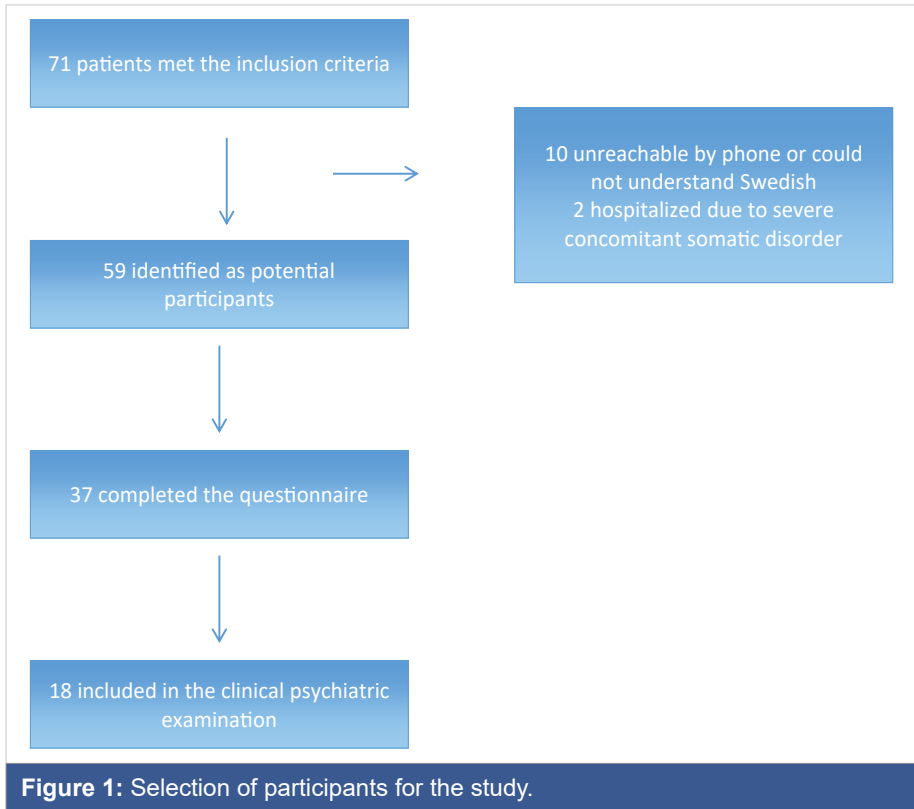

Table 1: Somatic morbidity in the 18 patients who completed the clinical psychiatric examination. RAS: Renal artery stenosis.

\begin{tabular}{|c|c|c|c|}
\hline Condition & $\begin{array}{c}\text { All } \\
(\mathbf{N}=\mathbf{1 8})\end{array}$ & $\begin{array}{c}\text { With RAS } \\
(\mathbf{N}=\mathbf{1 0})\end{array}$ & $\begin{array}{c}\text { Without RAS } \\
(\mathbf{N}=\mathbf{7})\end{array}$ \\
\hline Hypertension & 18 & 10 & 7 \\
\hline Cardiovascular disease & 15 & 10 & 4 \\
\hline Renal dysfunction & 5 & 3 & 2 \\
\hline Type 2 diabetes & 4 & 1 & 2 \\
\hline Atrophic kidney & 2 & 2 & 0 \\
\hline Chronic back pain & 2 & 2 & 0 \\
\hline Osteoarthritis & 2 & 1 & 1 \\
\hline Dyslipidaemia & 2 & 2 & 0 \\
\hline Hyperuricaemia & 2 & 2 & 0 \\
\hline Benign prostatic hyperplasia & 1 & 1 & 0 \\
\hline Atrial fibrillation & 1 & 1 & 0 \\
\hline Rheumatoid arthritis, RA & 1 & 1 & 0 \\
\hline Psoriasis & 1 & 1 & 0 \\
\hline Ulcerative colitis & 1 & 1 & 0 \\
\hline Stroke sequelae & 1 & 1 & 0 \\
\hline Migraine & 1 & 0 & 1 \\
\hline Chronic pancreatitis & 1 & 0 & 1 \\
\hline Asthma & 1 & 0 & 1 \\
\hline & 1 & 0 & 1 \\
\hline Chronic obstructive pulmonary disease & & & \\
\hline & 1 & 1 & 2 \\
\hline
\end{tabular}


Both the questionnaire part of the study and the clinical examination were performed a few weeks before the angiography, thus it was not known whether the patients suffered from significant RAS or not. Due to logistic reasons, 3 of 18 patients were examined shortly after their angiography (two to nine days) instead of before, but the psychiatric examiner was blinded concerning the result.

\section{The questionnaire}

The questionnaire included questions regarding: years with hypertension, previous anxiety, an anxiety disorder within the last year, previous treatment of anxiety, anxiety treatment within the last year, previous depression, depression within the last year, previous treatment of depression, depression treatment within the last year, treatment with psychotherapy, previous treatment with psychotropic medications, treatment with psychotropic medications within the last year. If they answered yes on the questions regarding psychotropic medications, they were asked to list the name of the drugs. The questionnaires were returned to the research unit in stamped addressed envelopes.

\section{Self-rating scales}

The self-rating Montgomery-Asberg Depression Rating Scale (MADRS-S) [25] consists of nine items scored from 0 to 6 points, giving a maximum of 54 points. A score of 13-19 indicates low-grade depression, 20-34 moderate depression and 35-54 severe depression.

The Hospital Anxiety and Depression scale (HAD) [26] consists of 14 items; seven covering anxiety and seven depression. Each item has a score from 0 to 3 points, giving a maximum score of 21 points for HAD anxiety and 21 points for HAD depression. A score of 0 to 7 points indicates no disorder, 8 to 10 points possible anxiety or depression, and 11-21 points most likely a disorder, on either subscale.

\section{Medical records}

Additional medical information on baseline p-renin, baseline p-aldosterone, previous and current medication and somatic comorbidity was collected from all patients' medical records after the questionnaire or the clinical psychiatric examination.

\section{Clinical psychiatric examination}

Patients were examined by a resident in psychiatry (LH). The examination consisted of a structured clinical interview regarding previous and current psychiatric disorders, treatment, previous medical conditions, and family history. The patients were diagnosed according to DSM-IV using the structured diagnostic tool International Neuropsychiatric Interview (M.I.N.I. 6.0). Patients were also rated according to the comprehensive psychopathological rating scale (CPRS) [27], from which the subscales Montgomery-Asberg Depression Rating Scale (MADRS) [28] and the Brief Scale of
Anxiety (BSA) [29] were extracted. In the CPRS each item is rated from zero to three points, and the score was therefore doubled to correspond to MADRS. The first seven patients also filled in the HAD during the clinical psychiatric examination.

\section{Angiography and endovascular intervention}

The mean pressure gradient between the aorta and the renal artery was measured during renal angiography, and if found to be $\geq 10 \mathrm{mmHg}$ the patient was diagnosed as having RAS and underwent PTRA, followed by stent placement [3032].

\section{Data collection at follow-up}

The follow-up part started after data had been collected on twelve patients. The first seven patients in the clinical psychiatric examination were also included in the follow-up. Thirty-two patients participated in the follow up part, of these 18 went through the psychiatric clinical examination at baseline.

In this part all patients filled in MADRS-S and HAD at baseline, together with the questionnaire and agreed to be contacted again after six months (follow up). At follow up the patients were contacted again by post six months after the angiography and intervention, and asked fill in the selfrating MADRS-S and HAD self-rating scales. Of the 32 patients included in the follow up 25 returned the envelopes. Of the 18 patients who went through the psychiatric clinical examination 16 returned the envelopes. During the same week, blood samples were collected in the morning for analysis of plasma (p-) aldosterone and p-renin. Patients also participating in the clinical psychiatric examination were interviewed by phone concerning changes in their medication.

\section{Laboratory analyses}

The standard methods for the analysis of p-aldosterone and p-renin were changed on November 17, 2014. Before November 17, 2014, p-aldosterone was determined using a radioimmunoassay (Aldosterone Coat-A-Count, DPC, CA, USA). The normal range for p-aldosterone is $110-860 \mathrm{pmol} / \mathrm{L}$, and the imprecision (coefficient of variation, CV) were $8.6 \%$ at $100 \mathrm{pmol} / \mathrm{L}$ and $5.2 \%$ at $750 \mathrm{pmol} / \mathrm{L}$. Plasma-renin was determined with the DiaSorin Liaison method (Liaison Renin, DiaSorin, Saluggia, Italy). The CV for this method were $4.4 \%$ at $27 \mathrm{mIU} / \mathrm{L}$ and $3.7 \%$ at 102 .

After November 17, 2014 p-aldosterone and p-renin were determined with the IDS-iSYS methods (Immunodiagnostics Systems Nordic a/s, Copenhagen, Denmark). The CV for the aldosterone method was/is $18 \%$ and $10 \%$ at 230 and 555 $\mathrm{pmol} / \mathrm{L}$. The normal range for renin using this method was 5-80 mIU/L, and the CV was $10 \%$ at both 14 and $92 \mathrm{mIU} / \mathrm{L}$.

All renin and aldosterone values prior to angiography were collected from patient files. These blood samples were all 
drawn prior to November 17,2014 and therefore analysed with the same method as described above. In the follow up blood samples were collected both prior to and after November 17, 2014. Fourteen out of 25 samples were determined with the previous method. Since the two renin methods showed good correlation $(\mathrm{R}=0.94)$, all $\mathrm{p}$-renin values from the RIA were recalculated to the IDS-iSys method. Aldosterone values were not recalculated, because the correlation between methods was deemed insufficient in the low normal concentration range $(<400 \mathrm{pmol} / \mathrm{L})$.

\section{Statistical analysis}

The Statistical Package for the Social Sciences (SPSS) Version 21.0 for Macintosh was used for all statistical analyses. The hypotheses were tested for two-tailed level of significance. The alpha level of significance was set at $p<$ 0.05 . Due to the relatively few participants, non-parametric statistical methods were used. The Mann-Whitney U test was used for group comparisons of independent samples, the Wilcoxon signed-rank test for comparison of paired samples, and Spearman's rho for correlation analysis. Cross tabulation and Pearson's chi square test were used to test differences in categorical data. All values are given as mean \pm 1 SD.

\section{Results}

\section{Characteristics}

Twenty-one of the 37 patients completing the questionnaire were found to have a pressure gradient of $\geq 10$ $\mathrm{mmHg}$ at angiography, indicating significant stenosis [33]. All 21 underwent PTRA and 18/21 also underwent successful renal artery stenting. The 15 patients in whom no significant pressure gradient was observed underwent diagnostic angiography only. In one patient the renal artery could not be reached during angiography due to severe atherosclerosis of the abdominal aorta. The presence of RAS could therefore not be determined. Ten of the 18 patients participating in the clinical psychiatric examination were found to have a pressure gradient of $\geq 10 \mathrm{mmHg}$, and were diagnosed as having significant stenosis [30]. All ten underwent PTRA, and 8/10 also underwent successful renal artery stenting.

The characteristics of the 37 patients who answered the questionnaire are given in Tables 2 and 3. Among these patients, 13 reported anxiety at least once during their life, and eight reported anxiety during the previous year. Eight patients reported previous depression, and four reported depression during the previous year.

\section{Psychiatric rating scales}

No significant difference was found in baseline MADRS-S scores between patients with RAS ( $=15$; MADRS-S $6.4 \pm 4.9$ ) and without RAS $(\mathrm{N}=9 ; 7.3 \pm 6.8)$ in the questionnaire part of the study. Furthermore, no significant differences were found in total baseline HAD scores, baseline HAD anxiety, or baseline HAD depression scores between patients with RAS $(\mathrm{N}=17)$ and those without RAS (N=11). See Table III for HAD scores.
In the questionnaire part of the study, eleven patients reported anxiety or depression within the past year. Among these, the means MADRS-S scores were $12.5 \pm 9.2(\mathrm{~N}=6)$ at baseline, and $13.4 \pm 7.5(\mathrm{~N}=9)$ at follow-up (NS). The corresponding total HAD scores were $13.7 \pm 6.2(\mathrm{~N}=9)$ at baseline and $13.0 \pm 5.5(\mathrm{~N}=9)$ at follow-up (NS).

MADRS-S and HAD scores for patients who took part in the clinical psychiatric examination and were diagnosed as currently having anxiety or depression $(\mathrm{N}=10)$ were analysed separately. All patients currently suffering from depression also had a current anxiety disorder. The MADRS-S scores for this group were $13.0 \pm 7.8(\mathrm{~N}=7)$ at baseline and $13.1 \pm 8.3$ $(\mathrm{N}=9)$ at follow-up (NS). The corresponding total HAD scores were $12.7 \pm 6.5(\mathrm{~N}=10)$ at baseline and $12.3 \pm 5.7(\mathrm{~N}=9)$ at follow-up (NS). The HAD anxiety and depression scores were $8.0 \pm 3.5$ and $4.7 \pm 3.5(\mathrm{~N}=10)$ at baseline, and $6.8 \pm 3.9$ and 5.6 $\pm 3.2(\mathrm{~N}=9)$ at follow-up (NS for both).

The 18 patients with RAS and successful PTRA and stenting were also analysed separately. Their HAD anxiety and depression scores were $3.9 \pm 2.8$ and $2.2 \pm 1.8$ at baseline $(\mathrm{N}=16)$, and $4.0 \pm 1.8$ and $2.7 \pm 2.4$ at follow-up $(\mathrm{N}=13)$ (NS for both).

\section{Hormones and blood pressure}

The mean value of p-renin prior to the intervention was $296 \pm 680 \mathrm{mIU} / \mathrm{L}(\mathrm{N}=13)$. The corresponding value for p-aldosterone was $372 \pm 539 \mathrm{pmol} / \mathrm{L}(\mathrm{N}=13)$. This means that renin, but not aldosterone, levels were increased compared to the normal range in all patients.

Table 2: Questionnaire results. Anxiety, depression and treatment according to the questionnaire in patients who only answered the questionnaire and in patients who also completed the clinical psychiatric examination. Statistics: Pearson's chi square test.

\begin{tabular}{|c|c|c|c|}
\hline & $\begin{array}{l}\text { Questionnaire, } \\
\text { only }(\mathrm{N}=19)\end{array}$ & $\begin{array}{l}\text { Clinical psychiatric } \\
\text { examination }(\mathrm{N}=18)\end{array}$ & $\mathbf{P}$ \\
\hline $\begin{array}{c}\text { Previous experience of anxiety } \\
\text { Yes/no/uncertain }\end{array}$ & $5 / 13 / 1$ & $8 / 8 / 2$ & 0.33 \\
\hline $\begin{array}{l}\text { Anxiety the last year } \\
\text { Yes/no/uncertain }\end{array}$ & $2 / 15 / 2$ & $6 / 11 / 1$ & 0.23 \\
\hline $\begin{array}{c}\text { Previous anxiety treatment } \\
\text { Yes/no/ }\end{array}$ & $1 / 18$ & $5 / 13$ & 0.063 \\
\hline $\begin{array}{l}\text { Anxiety treatment the last year. } \\
\text { Yes/no }\end{array}$ & $0 / 19$ & $1 / 17$ & 0.30 \\
\hline $\begin{array}{l}\text { Previous depression } \\
\text { Yes/no/uncertain }\end{array}$ & $0 / 16 / 3$ & $8 / 5 / 5$ & 0.001 \\
\hline $\begin{array}{l}\text { Depression the last year } \\
\text { Yes/no/uncertain }\end{array}$ & $0 / 18 / 1$ & $4 / 10 / 4$ & 0.018 \\
\hline $\begin{array}{l}\text { Previous depression treatment } \\
\text { Yes/no }\end{array}$ & $0 / 18$ & $8 / 10$ & 0.001 \\
\hline $\begin{array}{c}\text { Depression treatment the last } \\
\text { year } \\
\text { Yes/no }\end{array}$ & $0 / 19$ & $1 / 17$ & 0.30 \\
\hline $\begin{array}{c}\text { Treated with psychotherapy } \\
\text { Yes/no }\end{array}$ & $1 / 18$ & $1 / 17$ & 0.94 \\
\hline $\begin{array}{c}\text { Treated with psychotropic } \\
\text { medication } \\
\text { Yes/no }\end{array}$ & $4 / 15$ & $6 / 12$ & 0.40 \\
\hline $\begin{array}{c}\text { Current treatment with } \\
\text { psychotropic medication } \\
\text { Yes/no }\end{array}$ & $1 / 18$ & $0 / 17$ & 0.34 \\
\hline
\end{tabular}


Table 3: Characteristics of the 37 participants who completed the questionnaire. RAS: Renal artery stenosis, MADRS-S (Montgomery-Asberg Depression Rating Scale, Self-administered), HAD: Hospital Anxiety. Depression scale, BP: Blood pressure, Normal range of p-renin is 5-80 mlU/L and for p-aldosterone 110-860 pmol/L. Renin and aldosterone before angiography are presented. Mean $\pm 1 \mathrm{SD}$.

\begin{tabular}{|c|c|c|c|}
\hline & All $(\mathrm{N}=37)$ & With RAS (N=21) & Without RAS ( $N=15)$ \\
\hline Age & $64.1 \pm 12.0$ & $63.2 \pm 13.0$ & $64.9 \pm 11.1$ \\
\hline $\operatorname{Sex}(M / F)$ & $16 / 21$ & $12 / 9$ & $4 / 11$ \\
\hline MADRS-S & $7.6 \pm 6.9(\mathrm{~N}=25)$ & $6.4 \pm 4.9(\mathrm{~N}=15)$ & $7.3 \pm 6.8(\mathrm{~N}=9)$ \\
\hline MADRS-S follow-up & $8.8 \pm 7.0(\mathrm{~N}=25)$ & $6.9 \pm 4.8(\mathrm{~N}=16)$ & $10.4 \pm 7.7(\mathrm{~N}=8)$ \\
\hline HAD & $7.4 \pm 6.2(\mathrm{~N}=29)$ & $5.9 \pm 3.9(\mathrm{~N}=17)$ & $8.0 \pm 7.0(\mathrm{~N}=11)$ \\
\hline HAD follow-up & $8.3 \pm 5.6(\mathrm{~N}=24)$ & $6.4 \pm 3.3(\mathrm{~N}=15)$ & $9.9 \pm 6.4(\mathrm{~N}=8)$ \\
\hline HAD Anxiety & $4.6 \pm 3.9(\mathrm{~N}=29)$ & $3.8 \pm 2.7(\mathrm{~N}=17)$ & $4.8 \pm 4.5(\mathrm{~N}=11)$ \\
\hline HAD Anxiety follow-up & $4.8 \pm 3.2(\mathrm{~N}=24)$ & $3.9 \pm 2.0(\mathrm{~N}=15)$ & $5.3 \pm 3.5(\mathrm{~N}=8)$ \\
\hline HAD Depression & $2.8 \pm 2.8(\mathrm{~N}=29)$ & $2.1 \pm 1.8(\mathrm{~N}=17)$ & $3.2 \pm 3.1(\mathrm{~N}=11)$ \\
\hline HAD Depression - follow-up & $3.5 \pm 3.0(\mathrm{~N}=24)$ & $2.5 \pm 2.3(\mathrm{~N}=15)$ & $4.6 \pm 3.4(\mathrm{~N}=8)$ \\
\hline $\mathrm{BP}$ at admission $(\mathrm{mmHg})$ & $172 \pm 24 / 83 \pm 11(\mathrm{~N}=36)$ & $169 \pm 19 / 85 \pm 9(\mathrm{~N}=21)$ & $174 \pm 30 / 82 \pm 12(\mathrm{~N}=14)$ \\
\hline P-renin (mlU/L) & $296 \pm 680(N=13)$ & $623 \pm 934(N=6)$ & $10.4 \pm 7.9(\mathrm{~N}=6)$ \\
\hline P-aldosterone (pmol/L) & $372 \pm 539(\mathrm{~N}=13)$ & $511 \pm 755(\mathrm{~N}=6)$ & $283 \pm 276(N=6)$ \\
\hline Beta blocker & 30 & 17 & 12 \\
\hline Calcium channel blocker & 24 & 13 & 10 \\
\hline Angiotensin II receptor antagonist & 14 & 5 & 8 \\
\hline Thiazide diuretic & 13 & 6 & 6 \\
\hline Angiotensin-converting enzyme inhibitor & 12 & 7 & 5 \\
\hline Loop diuretic & 12 & 6 & 5 \\
\hline Imidazoline receptor blocker & 8 & 5 & 2 \\
\hline Alpha-adrenergic blocking agent & 7 & 4 & 2 \\
\hline Aldosterone receptor antagonist & 3 & 1 & 2 \\
\hline
\end{tabular}

P-renin level in patients with RAS (N=6) $(623 \pm 934 \mathrm{mIU} / \mathrm{L})$ was significantly higher than in patients without RAS $(\mathrm{N}=6)$ $(10.4 \pm 7.9 \mathrm{pmol} / \mathrm{L})(p=0.002)$, whereas no difference was found in p-aldosterone levels between the groups. See Table 3 for aldosterone levels.

The mean value of p-renin at the 6-month follow-up ( $\mathrm{N}=25)$ was $132 \pm 341 \mathrm{mIU} / \mathrm{L}$. No significant difference was found when comparing p-renin before and after stenting in patients with RAS who were successfully stented ( $\mathrm{N}=4, p=0.068)$.

Mean BP at admission was $172 \pm 24 / 83 \pm 11 \mathrm{mmHg}$ $(\mathrm{N}=36)$. No differences in BP were found between patients without RAS and those later diagnosed with RAS.

\section{Correlation analysis}

Values of p-aldosterone were available in patient records for 13 of 37 patients, of whom nine had MADRS-S scores. No significant correlation was found between p-aldosterone level and MADRS-S in this group. However, p-aldosterone was significantly correlated to the MADRS-S score in patients with RAS (N=5, $p=0.037)$.

No significant correlations were found between renin levels and HAD anxiety, HAD depression or MADRS-S scores at the six-month follow-up.

\section{Clinical psychiatric examination}

DSM-IV diagnosis: The characteristics of the examined patients $(\mathrm{N}=18)$ are given in Table 4 . Ten of the examined patients (56\%) met the criteria for an anxiety disorder. Two patients were diagnosed as currently suffering from
Table 4: Clinical psychiatric examination. DSM-IV diagnosis with International Neuropsychiatric Interview. CPRS: Comprehensive Psychopathological Rating Scale. MADRS: Subscale of the CPRS for depression, Montgomery-Asberg Depression Rating Scale. BSA: Subscale of CPRS for anxiety, Brief Scale of Anxiety.

\begin{tabular}{|c|c|c|c|}
\hline & All $(\mathrm{N}=18)$ & With RAS N=10) & $\begin{array}{l}\text { Without RAS } \\
\quad(\mathrm{N}=7)\end{array}$ \\
\hline Age Mean \pm SD & $65.4 \pm 12.1(\mathrm{~N}=18)$ & $67.9 \pm 10.3(\mathrm{~N}=10)$ & $60.7 \pm 14.5(\mathrm{~N}=7)$ \\
\hline $\operatorname{Sex}(M / F)$ & $8 / 10$ & $7 / 3$ & $1 / 6$ \\
\hline $\begin{array}{l}\text { Current psychiatric } \\
\text { diagnosis }\end{array}$ & 10 & 4 & 5 \\
\hline Any anxiety disorder & 10 & 4 & 5 \\
\hline $\begin{array}{c}\text { Generalized anxiety } \\
\text { disorder }\end{array}$ & 6 & 2 & 3 \\
\hline Social phobia & 6 & 2 & 3 \\
\hline Agoraphobia & 3 & 2 & 0 \\
\hline Panic disorder & 2 & 0 & 1 \\
\hline $\begin{array}{c}\text { Obsessive-compulsive } \\
\text { disorder }\end{array}$ & 2 & 1 & 0 \\
\hline Depression & 2 & 1 & 0 \\
\hline Alcohol dependence & 1 & 0 & 1 \\
\hline \multicolumn{4}{|l|}{$\begin{array}{c}\text { Previous psychiatric } \\
\text { diagnosis }\end{array}$} \\
\hline Depression $\mathrm{N}=9$ & 9 & 4 & 4 \\
\hline Panic disorder $\mathrm{N}=3$ & 3 & 0 & 2 \\
\hline MADRS Mean \pm SD & $9.9 \pm 8.4(\mathrm{~N}=18)$ & $6.9 \pm 6.8(\mathrm{~N}=10)$ & $10.9 \pm 4.2(\mathrm{~N}=7)$ \\
\hline BSA Mean \pm SD & $5.7 \pm 3.7(\mathrm{~N}=18)$ & $4.6 \pm 3.3(\mathrm{~N}=10)$ & $5.9 \pm 2.4(\mathrm{~N}=7)$ \\
\hline
\end{tabular}

depression. Eight of the patients did not meet the criteria for a current DSM-IV diagnosis.

Suicidality: Three of the eighteen patients (16.6\%) had attempted suicide. One had RAS, one could not be investigated, and one did not have RAS. The suicide attempts were 23 47 years ago. Two of three attempts had occurred during a depressive episode.

As the questionnaire part of the study did not include 
questions about previous suicide attempts, the suicide attempt rate was also calculated in relation to the 37 patients who completed the questionnaire, $3 / 37$ (8.1\%), in the 59 patients invited to participate in the study, 3/59 (5.1\%), and in all patients, $3 / 71(4.2 \%)$.

Correlation analysis: No correlations were found between p-renin or p-aldosterone levels and the CPRS subscales MADRS or BSA $(\mathrm{N}=6)$. Strong correlations were found between the self-rated MADRS-S score and the MADRS score resulting from the psychiatric examination $(\mathrm{R}=0.83, p=$ $0.001)$, and between the HAD anxiety score and the BSA score $(\mathrm{R}=0.80, p<0.001)$.

\section{Bias}

Thirty-seven patients completed the questionnaire, and of these 18 were examined by the resident in psychiatry. Cross tabulation was used to investigate whether the 18 patients examined differed from the patients participating only in the questionnaire part of the study. Significantly more patients who participated in the clinical psychiatric examination reported a history of depression than among those who did not take part in the psychiatric examination: $8 / 18$ versus $0 / 19$ ( $p$ $=0.001$ ). No significant difference was found in the reported history of anxiety between the patients who participated in the clinical psychiatric examination and those who did not take part in the psychiatric examination: $8 / 18$ versus $5 / 19$ $(\mathrm{p}=\mathrm{NS})$ (Table 2).

\section{Discussion}

In this study we found a high rate of anxiety disorders (56\%) and previous suicide attempts (17\%) in patients with suspected RAS, when evaluated by psychiatric examination. We therefore suggest that anxiety disorders are more common in patients with suspected RAS than in the general population. The lifetime prevalence of an anxiety disorder in the general population is between $10 \%$ and $29 \%$ [2,3]. The anxiety rate in patients with suspected RAS may also be higher than in patients with hypertension in general. In a study based on over two million patients in Sweden, investigating registered diagnoses over a five-year period, it was found that $7.1 \%$ of the patients with hypertension also had a diagnosis of anxiety, compared with $6.3 \%$ of normotensive patients [34]. Patients with PA and RAS both overproduce aldosterone. A higher ratio of anxiety has been found in patients with PA $(12 / 23$ $=52 \%)$ than in those with essential hypertension $(4 / 23=$ 17\%) [24]. Few studies have been carried out to investigate psychiatric comorbidity in RAS patients. However, it was shown in a recent case report [35] that successful PTRA in a patient with RAS cured problems of anxiety, negativism and asthenia. Renin and aldosterone levels were normalized one month after the intervention, and the psychiatric symptoms had disappeared.

Depression, on the other hand, was not as frequent as anxiety in our study. Only 2 out of 18 (11\%) patients who underwent the psychiatric examination met the DSM-IV criteria for current depression. In a study by Sandstrom, et al., the prevalence of depression in patients with hypertension was found to be $9.6 \%$, compared to $6.9 \%$ in normotensive patients [34].

In spite of the high rate of anxiety disorders the patients in the present study had relatively low MADRS-S and HAD scores. The HAD anxiety score for patients who met the DSM-IV criteria for diagnosis of an anxiety disorder was 8.0 \pm 3.5 , corresponding to a possible anxiety disorder [26]. The discrepancy between the M.I.N.I. interview score and the selfrating scores may reflect the better evaluation of anxiety in the M.I.N.I. interview than the self-rated HAD scores.

An important limitation of this study concerning the high rate of anxiety disorders and suicide attempts is that it could be argued that only patients with psychiatric illness were interested in taking part in the clinical psychiatric examination, and that the high occurrence of psychiatric morbidity might, therefore, be a result of selection bias. Therefore, cross tabulation was used. This showed that selfreported anxiety by those completing the questionnaire was not over-reported in the group of patients who underwent the psychiatric examination, compared to those who only participated in the questionnaire part of the study. However, patients participating in the psychiatric examination reported previous depression more frequently than patients who only completed the questionnaire. This suggests that patients with previous depression were more prone to participate in the clinical psychiatric examination.

Questions about previous suicide attempts were not included in the questionnaire in this study, and thus cross tabulation could not be used to investigate possible selection bias regarding suicide attempts. The suicide attempts had occurred 23-47 years ago, before the onset of hypertension. The occurrence of a previous suicide attempt in this study is estimated between $4.2 \%$ and $16.6 \%$. This should be compared with a lifetime prevalence of $2.7 \%$ reported for suicide attempts in the general population [36]. Thus, it is possible that the rate of previous suicide attempts is increased in patients with suspected RAS.

Patients suffering from RAS exhibit over-activation of their RAAS [37]. In this study we found increased renin levels but not aldosterone levels, and that patients with RAS had significantly higher renin levels than those without RAS. The reason for this discrepancy may be effects of antihypertensive medication. It should also be mentioned that when the study was designed, it was assumed that renin and aldosterone levels were determined in all patients remitted for renal angiography, however, this was the case in only 13 of 37 patients. The fact that renin, but not aldosterone, levels were elevated in RAS patients is probably explained by the fact that patients both with and without a significant pressure gradient in the renal artery showed some degree of kidney dysfunction. 
One of our hypotheses was that symptoms of depression or anxiety would be reduced after endovascular dilatation in RAS patients. However, when RAS patients who were successfully stented rated their symptoms of anxiety and depression before and 6 months after the intervention, no such effect was found.

The patients included in this study had a large number of somatic disorders, and medication may also have affected the results. It has generally been thought that treatment with beta-blockers may induce symptoms of depression. However, recent studies do not support this [38]. Another limitation is the fact that 10 patients could not be included in the study as they were impossible to reach by phone or did not speak Swedish. However, this limitation applies to all studies using questionnaires.

The mechanisms by which overactivation of the RAAS can have depressive and anxiogenic effects are unclear. MR are found in the hippocampus, amygdala and nucleus accumbens ( [16]. Animal studies have shown that aldosterone can pass through the blood-brain barrier [39]. Rats treated with aldosterone exhibit symptoms of depression and anxiety $[17,18]$, and we have previously found a positive correlation between depressive symptoms and aldosterone concentration in humans [40]. In the present study we also found a positive correlation between the MADRS-S score and aldosterone level in patients with RAS, although the number of patients was small.

In $90 \%$ of cases, RAS is due to atherosclerosis. Patients with general atherosclerosis have elevated levels of cytokines, and patients with RAS have been found to exhibit elevated inflammatory activity. Cytokines are elevated compared to healthy controls in all patients undergoing renal angiography - both those with, and those without, a pressure gradient between the aorta and the renal artery [31].

Increased levels of cytokines have also been reported in patients with depression [41], and there is evidence that inflammation is involved in depressive pathophysiology, although the extent is debated [42]. The role of neuroinflammation in anxiety disorders, on the other hand, has been less investigated, but the overproduction of cytokines, similar to that in depression, has also been reported in this setting [43].

Inflammation has also been linked to suicidal behaviour $[44,45]$. Although the possible higher incidence of previous suicide attempts observed in this study occurred before the onset of hypertension. Increased inflammatory activity in these patients might have been a risk factor for both suicide and somatic illness. This should be investigated in future studies.

The results of this study suggest that patients with suspected RAS have a high psychiatric comorbidity, as 56\% of the patients undergoing psychiatric examination met the DSM-IV criteria for a current anxiety disorder. Previous studies have also found an increased prevalence of anxiety in patients with hypertension. In light of these findings, it may be important to examine the occurrence of anxiety disorders in patients with treatment-resistant hypertension.

We were not able to find any improvement in depressive or anxiety symptoms after PTRA, followed by stent placement. As the number of patients included in this study was small, and no control group was used, more extensive studies are warranted.

\section{Acknowledgement}

This study was supported with grants from Region Skane and Lund University. We would like to thank the research unit at the Department of Vascular Diseases for logistic support. We would also like to thank Lena Brundin, Cecilie Bay-Richter and Shorena Janelidze for input on the design of the study..

\section{References}

1. Kessler RC, Berglund P, Demler O, Jin R, Koretz KR, et al. The epidemiology of major depressive disorder: results from the National Comorbidity Survey Replication (NCS-R). JAMA. 2003; 289: 3095-3105. PubMed: https://pubmed.ncbi.nlm.nih.gov/12813115/

2. Kessler RC, Berglund $P$, Demler $O$, Jin R, Merikangas $K R$, et al Lifetime prevalence and age-of-onset distributions of DSM-IV disorders in the National Comorbidity Survey Replication. Arch Gen Psychiatry. 2005; 62: 593-602.

PubMed: https://pubmed.ncbi.nlm.nih.gov/15939837/

3. Rorsman BO. Hagnell, J. Lanke and L. Ojesjo. Incidence of anxiety in the Lundby Study: changes over time during a quarter of a century. Neuropsychobiology. 1987; 18: 13-20.

PubMed: https://pubmed.ncbi.nlm.nih.gov/3444521/

4. Mulinari S. Monoamine theories of depression: historical impact on biomedical research. J Hist Neurosci. 2012; 21: 366-392.

PubMed: https://pubmed.ncbi.nlm.nih.gov/22947380/

5. Bao AM, Meynen G, Swaab DF. The stress system in depression and neurodegeneration: focus on the human hypothalamus. Brain Res Rev. 2008; 57: 531-553.

PubMed: https://pubmed.ncbi.nlm.nih.gov/17524488/

6. Dantzer RJ. O'Connor C, Freund GG, Johnson RW, Kelley KW. From inflammation to sickness and depression: when the immune system subjugates the brain. Nat Rev Neurosci. 2008; 9: 46-56.

PubMed: https://pubmed.ncbi.nlm.nih.gov/18073775/

7. Kunzel HE. Psychopathological symptoms in patients with primary hyperaldosteronism--possible pathways. Horm Metab Res. 2012; 44: 202-207.

PubMed: https://pubmed.ncbi.nlm.nih.gov/22351473/

8. Ferrao FM, Lara LS, Lowe J. Renin-angiotensin system in the kidney: What is new? World J Nephrol. 2014; 3: 64-76.

PubMed: https://pubmed.ncbi.nlm.nih.gov/25332897/

9. DeForrest JM, Knappenberger RC, Antonaccio MJ, Ferrone RA, Creekmore JS. Angiotensin II is a necessary component for the development of hypertension in the two kidney, one clip rat. Am J Cardiol. 1982; 49: 1515-1517.

PubMed: https://pubmed.ncbi.nlm.nih.gov/6280481/

10. Basso N, Terragno NA. History about the discovery of the reninangiotensin system. Hypertension. 2001; 38: 1246-1249. PubMed: https://pubmed.ncbi.nlm.nih.gov/11751697/ 
11. Caps MT, Zierler RE, Polissar NL, Bergelin RO, Beach KW, et al. Risk of atrophy in kidneys with atherosclerotic renal artery stenosis. Kidney Int. 1998; 53: 735-742.

PubMed: https://pubmed.ncbi.nlm.nih.gov/9507221/

12. Gruntzig A, Kuhlmann U, Vetter W, Lutolf U, Meier B, et al. Treatment of renovascular hypertension with percutaneous transluminal dilatation of a renal-artery stenosis. Lancet 1. 1978; 1: 801-802. PubMed: https://pubmed.ncbi.nlm.nih.gov/85817/

13. ASTRAL Investigators, Wheatley K, Ives N, Gray R, Kalra PA, et al. Revascularization versus medical therapy for renal-artery stenosis. N Engl J Med. 2009; 361: 1953-1962.

PubMed: https://pubmed.ncbi.nlm.nih.gov/19907042/

14. Cooper CJ, Murphy TP, Cutlip DE, Jamerson K, Henrich W, et al Stenting and medical therapy for atherosclerotic renal-artery stenosis. N Engl J Med. 2014; 370: 13-22.

PubMed: https://pubmed.ncbi.nlm.nih.gov/24245566/

15. Gomez-Sanchez EP. Brain mineralocorticoid receptors in cognition and cardiovascular homeostasis. Steroids. 2014; 91: 20-31.

PubMed: https://pubmed.ncbi.nlm.nih.gov/25173821/

16. Klok MD, Alt SR, Irurzun Lafitte AJ, Turner JD, Lakke EA, et al. Decreased expression of mineralocorticoid receptor mRNA and its splice variants in postmortem brain regions of patients with major depressive disorder. J Psychiatr Res. 2011; 45: 871-878. PubMed: https://pubmed.ncbi.nlm.nih.gov/21195417/

17. Hlavacova N, Jezova D. Chronic treatment with the mineralocorticoid hormone aldosterone results in increased anxiety-like behavior. Horm Behav. 2008; 54: 90-97.

PubMed: https://pubmed.ncbi.nlm.nih.gov/18377905/

18. Bay-Richter C, Hallberg L, Ventorp F, Janelidze S, Brundin L. Aldosterone synergizes with peripheral inflammation to induce brain IL-1beta expression and depressive-like effects. Cytokine. 2012; 60: 749-754. PubMed: https://pubmed.ncbi.nlm.nih.gov/22981168/

19. Yau JL, Hibberd C, Noble J, Seckl JR. The effect of chronic fluoxetine treatment on brain corticosteroid receptor mRNA expression and spatial memory in young and aged rats. Brain Res Mol Brain Res. 2002; 106: 117-123.

PubMed: https://pubmed.ncbi.nlm.nih.gov/12393271/

20. Seckl JR, Fink G. Antidepressants increase glucocorticoid and mineralocorticoid receptor mRNA expression in rat hippocampus in vivo. Neuroendocrinology. 1992; 55: 621-626.

PubMed: https://pubmed.ncbi.nlm.nih.gov/1321353/

21. Yau JL, Noble J, Hibberd C, Seckl JR. Short-term administration of fluoxetine and venlafaxine decreases corticosteroid receptor mRNA expression in the rat hippocampus. Neurosci Lett. 2001; 306: 161-164. PubMed: https://pubmed.ncbi.nlm.nih.gov/11406320/

22. Emanuele E, Geroldi D, Minoretti P, Coen E, Politi P. Increased plasma aldosterone in patients with clinical depression. Arch Med Res. 2005; 36: 544-548.

PubMed: https://pubmed.ncbi.nlm.nih.gov/16099336/

23. Sonino N, Fallo F, Fava GA. Psychological aspects of primary aldosteronism. Psychother Psychosom. 2006; 75: 327-330.

PubMed: https://pubmed.ncbi.nlm.nih.gov/16899970/

24. Sonino N, Tomba E, Genesia ML, Bertello C, Mulatero P, et al. Psychological assessment of primary aldosteronism: a controlled study. J Clin Endocrinol Metab. 2011; 96: E878-883.

PubMed: https://pubmed.ncbi.nlm.nih.gov/21389142/

25. Svanborg P, Asberg M. A new self-rating scale for depression and anxiety states based on the Comprehensive Psychopathological Rating Scale. Acta Psychiatr Scand. 1994; 89: 21-28.

PubMed: https://pubmed.ncbi.nlm.nih.gov/8140903/

26. Zigmond AS, Snaith RP. The hospital anxiety and depression scale. Acta Psychiatr Scand. 1983; 67: 361-370.

PubMed: https://pubmed.ncbi.nlm.nih.gov/6880820/
27. Asberg M, Montgomery SA, Perris C, Schalling D, Sedvall G. A comprehensive psychopathological rating scale. Acta Psychiatr Scand Suppl. 1978; 5-27.

PubMed: https://pubmed.ncbi.nlm.nih.gov/277059/

28. Montgomery SA, Asberg M. A new depression scale designed to be sensitive to change. Br J Psychiatry. 1979; 134: 382-389.

PubMed: https://pubmed.ncbi.nlm.nih.gov/444788/

29. Tyrer P, Owen RT, Cicchetti DV. The brief scale for anxiety: a subdivision of the comprehensive psychopathological rating scale. $J$ Neurol Neurosurg Psychiatry. 1984; 47: 970-975.

PubMed: https://pubmed.ncbi.nlm.nih.gov/6481391/

30. Alhadad A, Mattiasson I, Ivancev K, Lindh M, Gottsater A, et al. Mean pressure gradient in renal artery stenosis (RAS) before and after percutaneous transluminal renal angioplasty (PTRA) regarding initial effect and long-term outcome. Useful or not? J Renovasc Dis. 2006; 7-13.

31. Alhadad A, Guron G, Fortuna-Nowakowska E, Saeed A, Mattiasson I, et al. Renal angioplasty causes a rapid transient increase in inflammatory biomarkers, but reduced levels of interleukin- 6 and endothelin-1 1 month after intervention. J Hypertens. 2007; 25: 1907-1914. PubMed: https://pubmed.ncbi.nlm.nih.gov/17762656/

32. Alhadad A, Mattiasson I, Ivancev K, Lindblad B, Gottsater A. Predictors of long-term beneficial effects on blood pressure after percutaneous transluminal renal angioplasty in atherosclerotic renal artery stenosis. Int Angiol. 2009; 28: 106-112.

PubMed: https://pubmed.ncbi.nlm.nih.gov/19367240/

33. Alhadad A, Mattiasson I, Ivancev K, Lindh M, Gottsater A, et al Does the pressure gradient in renal artery stenosis before and after percutaneous transluminal renal angioplasty predict initial and longterm outcome? J Renovasc Dis. 2006; 7-13.

34. Sandstrom YK, Ljunggren G, Wandell P, Wahlstrom L, Carlsson AC. Psychiatric comorbidities in patients with hypertension - a study of registered diagnoses 2009-2013 in the total population in Stockholm County, Sweden. J Hypertens. 2016; 34: 414-420

PubMed: https://pubmed.ncbi.nlm.nih.gov/26766563/

35. Mazza A, Ravenni R, Armigliato M, Rossetti C, Schiavon L, et al. Mood Disorders in Uncontrolled Hypertension Despite Multiple AntiHypertensive Medications: Searching for a Link. High Blood Press Cardiovasc Prev. 2016; 23: 41-46.

PubMed: https://pubmed.ncbi.nlm.nih.gov/26729327/

36. Nock MK, Borges G, Bromet EJ, Alonso J, Angermeyer M, et al. Crossnational prevalence and risk factors for suicidal ideation, plans and attempts. Br J Psychiatry. . 2008; 192: 98-105. PubMed: https://pubmed.ncbi.nlm.nih.gov/18245022/

37. Kotliar C, Inserra F, Forcada P, Cavanagh E, Obregon S, et al. Are plasma renin activity and aldosterone levels useful as a screening test to differentiate between unilateral and bilateral renal artery stenosis in hypertensive patients? J Hypertens. 2010; 28: 594-601.

PubMed: https://pubmed.ncbi.nlm.nih.gov/20104188/

38. Ko DT, Hebert PR, Coffey CS, Sedrakyan A, Curtis JP, et al. Betablocker therapy and symptoms of depression, fatigue, and sexual dysfunction. JAMA. 2002; 288: 351-357.

PubMed: https://pubmed.ncbi.nlm.nih.gov/12117400/

39. Yu Y, Wei SG, Zhang ZH, Gomez-Sanchez E, Weiss RM, et al. Does aldosterone upregulate the brain renin-angiotensin system in rats with heart failure? Hypertension. 2008; 51: 727-733.

PubMed: https://pubmed.ncbi.nlm.nih.gov/18227408/

40. Hallberg L, Westrin A, Isaksson A, Janelidze S, Traskman-Bendz L, et al. Decreased aldosterone in the plasma of suicide attempters with major depressive disorder. Psychiatry Res. 2011; 187: 135-139. PubMed: https://pubmed.ncbi.nlm.nih.gov/20797799/

41. Dowlati $Y$, Herrmann N, Swardfager W, Liu H, Sham L, et al. A metaanalysis of cytokines in major depression. Biol Psychiatry 67: 446-457. PubMed: https://pubmed.ncbi.nlm.nih.gov/20015486/ 
42. Raison $\mathrm{CL}$, Miller $\mathrm{AH}$. Is depression an inflammatory disorder? Curr Psychiatry Rep. 2011; 13: 467-475.

PubMed: https://pubmed.ncbi.nlm.nih.gov/21927805/

43. Furtado M, Katzman MA. Neuroinflammatory pathways in anxiety, posttraumatic stress, and obsessive compulsive disorders. Psychiatry Res. 2015; 229: 37-48.

PubMed: https://pubmed.ncbi.nlm.nih.gov/26296951/

44. Brundin L, Erhardt S, Bryleva EY, Achtyes ED, Postolache TT. The role of inflammation in suicidal behaviour. Acta Psychiatr Scand. 2015; 132: 192-203.

PubMed: https://pubmed.ncbi.nlm.nih.gov/26256862/

45. Ventorp F, Gustafsson A, Traskman-Bendz L, Westrin A, Ljunggren L. Increased Soluble Urokinase-Type Plasminogen Activator Receptor (suPAR) Levels in Plasma of Suicide Attempters. PLoS One. 2015; 10 : e0140052. PubMed: https://pubmed.ncbi.nlm.nih.gov/26451727/ 